\section{The Health Care System and Training Specialist in Intensive Care Medicine and Emergency in Cuba}

\author{
Pedro Luis Véliz Martinez \\ National Council of Scientific Societies of \\ Health, Cuba
}

Corresponding author:

Pedro Luis Véliz Martinez

\section{Abstract}

Introduction: The contemporary social development requires the presence of specialists to ensure the quality of health services.

Objective: To characterize the system of care and specialty medical training in intensive care medicine and emergency in Cuba.

Methods: A historical research was conducted; the analytic-synthetic, historical and logical, and system approach modeling methods were used. Opinions of key informants and previous research concentrated. It was held a socio-demographic and influence of the specialty in the Cuban national health system study.

Results: Cuba has a health behavior of developed countries. There are 17 mobile medical emergency centers, 120 municipal intensive areas and 109 hospital intensive care rooms with 1906 beds. There are 3286 specialists and residents working on stage specialty, which have increased in the last decade. There have been two ways of training specialists, with two output profiles: adult and pediatric, incorporating emergency profile is necessary. The role played by the Cuban Society of Intensive Care and Emergency Medicine, and the system of care specialty in Cuba is expressed.

Conclusion: A continuous and progressive patient care with emergencies or emergencies, severe or critical, passing through the healthcare network and where there is always a specialist who combines the knowledge and skills of intensive medicine emergency medicine and emergencies is provided. It is necessary to update the curriculum by increasing the occupational profile and work scenarios.

Keywords: Intensive care; Emergency medicine; Professional competence; Clinical competence; Continuing medical education; Curriculum; Internship and residency; Cuba

\section{” urgrav@infomed.sld.cu}

Director of the National Council of Scientific Societies of Health, President of the Cuban Society of Intensive Care and Emergency Medicine, Doctor in medicine, Specialist in Intensive and Emergency Medicine, Specialist in Internal Medicine, Master in Medical Emergencies, Master in Medical Education, Assistant Professor and Assistant Researcher at the University of Medical Sciences of Havana professor, Cuba.

Tel: 5352700835

Citation: Martinez PLV. The Health Care System and Training Specialist in Intensive Care Medicine and Emergency in Cuba. J Intensive \& Crit Care 2016, 2:3.

\section{Introduction}

The contemporary social development increasingly requires the presence of well-trained medical specialists to ensure the quality of health services in line with the ever increasing demands of the population [1].

The specialty graduate is one of the training processes that provide college graduates the acquisition, updating, deepening and upgrading of skills for professional performance required for a job, in keeping with the needs of economic, social development and cultural life. Oriented to satisfy demands made by the occupational profile, with the aim of achieving a high degree of professional development in their graduates [2]. In Cuban medicine, conceived as a continuation of studies at the end of undergraduate training, as part of the medical improvement, with more specialized nature necessary for a high level of performance, solidity in the ethical-moral and high grade scientific and technical principles.

In the training of specialists in medicine, medical residencies has been the educational modality most used in the world, considered as a system of professional education for graduates of the faculties and schools of Medicine, structured in the form 
of in-service training in a particular specialty, full-time, in which learning is constructed through practice in a health service, with increasing responsibilities, under constant supervision, acquiring at the same time work habits and a definite term each especialidad [1].

Intensive care medicine in the world has been characterized from the beginning by its ability to identify and dynamically assimilate clinical situations seriously ill or critical, in which the predominant physiological and where small changes can lead to a serious global deterioration instability, with organ damage irreversible or death, so it is necessary to exercise strict controls over them and use special and immediate treatment. The specialty has taken rapid scientific, technological changes and a harmonious relationship between human, technological, pharmacological and arquitectonical resources [3-5].

Intensive care medicine and emergency (ICME) emerged in Cuba in the late $60 \mathrm{~s}$ and was initially developed as a clinical subspecialty until it is recognized as a specialty in 2000, reaching its theoretical body, skill system, own practical impact and relevance social [6].

A 16 year established specialty ICME [7] given its evolution in Cuba and medical solidarity that is done abroad, occupational profile update is required, functions and skills that doctors develop in services [6].

The aim of the study is to characterize the care system and medical specialty training in emergency medicine and intensive Cuba to allow, in the future, propose a model of ICME for specialist skills.

\section{Methods}

A historical research of the emergence and development of related specialties Intensive Care and Emergency in the world and in Cuba was made. The analytic-synthetic to decompose on all parties know the roots and based on this analysis, the synthesis was performed to reconstruct and explain method was used. The logical- historical method was used to characterize historical periods.

A review and study of curriculum ICME specialty in Cuba, regulations and documents in order to identify and analyze legal instruments, concepts, approaches and performance was made. The views of medicals, as key informants who participated in national workshops for the development of the specialty [8] and two investigations by Véliz and collaborators on functions and technical assistance specialist in Cuba [9] ICME and skills focused profesionales [10].

A socio-demographic study of the Cuban population and the influence of ICME specialty in medical care you get are made, characterizing its influence on the Cuban national health system.

Abstraction and system approach to state care system specialist ICME in Cuba for optimal professional performance - modeling that enabled the realization process was used.

\section{Results}

The Cuban population is made up of 11238661 inhabitants, distributed in 15 provinces and 168 municipalities. The urbanization rate is $76.8 \%$ and $19.4 \%$ of people aged 60 and over age [11].

Although Cuba is a bit industrialized country with few natural resources and low per capita GDP, it is estimated that the Human Development Index (HDI) of 0.769 , considered high and ranks 67 among 187 countries, which influences undoubtedly health level reached by the population cubana $[12,13]$. Therefore among its top five causes of death are: heart disease, malignant tumors, cerebrovascular disease, influenza and pneumonia, and accidents, with mortality behavior similar to that of the most development countries [11].

In 2015, 99,694 deaths were reported, mainly at the expense of deceased aged 65 and older, given the existing population aging. Heart disease had a rate of 218.3 per 100000 inhabitants, followed by malignant tumors death rate is 215.0 , both causes account for $49 \%$ of all deaths in the year 2015 [11].

The National Health System has 151 hospitals and 12 research institutes for health care, with a total of 45,892 beds, a ratio of 4.1 beds per 1000 inhabitants, which are 109 rooms conventional intensive therapy of polyvalent type or monovalent (32 pediatric and adult 77), which are distributed in the manner presented in Table 1.

There are 1546 beds in 360 adults and therapies in pediatric therapies, for a total of 1906 beds, representing $4.15 \%$ of total beds for medical care in all specialties in intensive therapies.

The health care system specialty ICME is composed of 120 municipal intensive areas, [11] which are units of two to four beds with resolving power for emerging situations in primary health care (PHC) for medical assistance urgencies and emergencies in municipalities that do not have intensive therapies intended for the initial care of critically ill patients, who after starting stabilizing treatment, he moved to the intensive care convencionales [14].

The system of transfer of critically ill patients is done through the system of mobile medical emergency, with types of ambulances for emergency care and emergencies, which have medical equipment for advanced life support, and that are controlled through medicalized coordinator, who is based in the provincial mobile medical emergency center (Table 2).

In the first decade of the century scenarios and occupational profile of the ICME: a care in intensive care units (ICU), municipal intensive areas were added areas of vital support for prehospital care were established urgencies and emergencies throughout the PHC; a coordinated and specialized transfer system was established by the mobile medical emergency, began operating the monovalent ICU for the treatment of cardiac and acute brain-vascular illnesses, they differ in various hospitals in the areas of attention to the urgent needs of the emergency and request of its authorities, international solidarity extended to the areas dedicated to emergencies, emergency and intensive care specialists to undertake ICME experienced medical care in these countries $[4,6,15,16]$.

Since 2005, the Henry Reeve medical contingent is based, as proposed Cuba to provide medical aid to USA after Hurricane 
Katrina, which has been composed of multiple specialists in ICME, specializing in medical emergencies and attention to natural disasters and epidemics have become real threats globales [17-19].

The training of human resources for health in Cuba occurs in 13 universities and 25 medical schools, four schools of dentistry, one nurse, one health technology, three technology and nursing, 15 branches of medical sciences, Latin American School of Medicine and the National School of Public Health [11].

In correspondence with the historical and social development that had the ICME as a specialty in Cuba [6], in the period 1985-1990 postgraduate training was initiated through a professionalizing graduate a year directed to prepare young specialists specialties like internal medicine, pediatrics, anesthesiology and resuscitation, general surgery, cardiology, and others, which provided a suitable staff to cover therapies and bring the therapeutic and intensive surveillance to emergency services and mobile units advanced life support [4, 20,21], that specialists were called "dedicated".

Adults and pediatrics [7] which proposed train a highly qualified professional, able: in 2000 specializing in ICME, which was conceived as a clinical specialty, with a three-year residency and two output profiles is officially established to integrate aspects with intensive care emergencies and urgencies médicas [20]. The curriculum has a period of basic training medical - surgical one year taking place in intermediate care units and two years, specific ICU; with a curriculum has 5984 h, spread over 16 modules, where the resident provides care services under the supervision of a tutor or teacher, and meets the requirements for the regime residences in health sciences $[7,21]$.

At present there are work-related areas of health care specialty, a total of 3286 professionals distributed as follows [11] (Table 3):

Dedicated specialists can become specialists ICME through theoretical and practical and presentation of results of examinations work before a tribunal constituted for this purpose.

Medical residency is carried out in all provinces, except in the provinces Artemisa and Mayabeque, their hospitals have not been accredited for teaching in the field, they do not comply with the requirements for the regime residences.

Research conducted by the author with groups of experts, managers, academics and informants claves [9, 10] gives the following results: the need for a third output profile for emergencies, and thus the rotation during residency in these areas.

In this first decade of the century was held for several years a Master of Medical Emergencies, which was widely accepted by doctors and nursing professionals, covering a gap in the specialty and providing knowledge about emergency and medical emergencies, which in the world today is the specialty of Emergency Medicine and Emergency, with a strong practical component, with a variant of organization of blended learning, allowed the formation of hundreds of professionals who have contributed to scientific development of the ICME in the country. The master was initially conceived for the scientific development

Table 1 Intensive care units by hospital types and total of beds.

\begin{tabular}{|c|c|c|c|c|c|c|c|c|}
\hline \multirow{2}{*}{ Intensive Care Units } & \multicolumn{6}{|c|}{ Hospital Types } & \multirow{2}{*}{ Total of units } & \multirow{2}{*}{ Total of beds } \\
\hline & General & Clínical Surgical & Pediatrics & Orthopedic & Mother-Childs & Others & & \\
\hline Adults & 40 & 30 & - & 2 & - & 5 & 77 & 1546 \\
\hline Pediatrics & 10 & - & 19 & - & 1 & 2 & 32 & 360 \\
\hline Total & 50 & 30 & 19 & 2 & 1 & 7 & 109 & 1906 \\
\hline
\end{tabular}

Table 2 Mobile medical emergency centers and intensive care units by specialty, type and province, 2015.

\begin{tabular}{|c|c|c|c|c|}
\hline \multirow{2}{*}{ Province } & \multicolumn{2}{|c|}{ Intensive Care Units } & \multirow{2}{*}{ Municipal Intensive Areas } & \multirow{2}{*}{ Mobile Emergency Centers } \\
\hline & Pediatrics & Adults & & \\
\hline Pinar del Río & 1 & 2 & 10 & 1 \\
\hline Artemisa & 1 & 3 & 7 & 1 \\
\hline La Habana & 10 & 19 & 10 & 2 \\
\hline Mayabeque & 1 & 2 & 9 & 1 \\
\hline Matanzas & 1 & 7 & 11 & 1 \\
\hline Villa Clara & 1 & 8 & 8 & 1 \\
\hline Cienfuegos & 1 & 1 & 7 & 1 \\
\hline Sancti Spíritus & 1 & 4 & 1 & 1 \\
\hline Ciego de Ávila & 2 & 2 & 9 & 1 \\
\hline Camagüey & 1 & 7 & 8 & 1 \\
\hline Las Tunas & 1 & 2 & 4 & 1 \\
\hline Holguín & 2 & 5 & 11 & 1 \\
\hline Granma & 2 & 3 & 10 & 1 \\
\hline Santiago de Cuba & 4 & 9 & 7 & 1 \\
\hline Guantánamo & 2 & 2 & 8 & 1 \\
\hline Isla de la Juventud & 1 & 1 & - & 1 \\
\hline Total & 32 & 77 & 120 & 17 \\
\hline
\end{tabular}


Table 3 Specialists and residents in intensive care and emergencies in Cuba, 2015.

\begin{tabular}{|c|c|}
\hline Specialists & Quantity \\
\hline Dedicated specialists & 1994 \\
\hline ICME specialists & 752 \\
\hline ICME residents & 540 \\
\hline Total & 3286 \\
\hline
\end{tabular}

of the first level of care the NHS, but it was very well received by the rest of the professionals of hospitals and research institutes, which also contributed to its development and generalización [6].

Parallel to all these processes, also in the first decade of the century is created and developed by the Cuban Society of Intensive Care and Emergency (Socumie) that groups linked to emergency professional, emergency and intensive care in the country, it has chapters in all provinces, and assumes the organization and development of various conferences, events and important scientific activities for development of the specialty in Cuba and Latin America; the Cuban Journal of Intensive Care and Emergency Medicine, periodical of society emerges; and three web pages, one dedicated to pediatric intensive care, other emergency and intensive care for adults and one for the program donation and organ transplants are established, which have contributed to provide systematic and updated scientific information, to disclose the scientific advances in the field and its main activities in Cuba and in the world.

Research by the autor $[9,10]$ with scientific processes modeling, system approach, induction, deduction, analysis and synthesis, and abstraction, have allowed him to set the system care specialist ICME applied today in Cuba it is that this professional is able to provide a continuous and progressive patient care with emergencies or emergencies from any source, serious or critical, where the patient is passing through the various stages of the healthcare network, from emergency departments and an emergency to the ICU, going even prehospital care and mobile medical emergency, where there will be a ICME specialist who devotes all his time to specialized care, with optimal performance in the diagnosis, stabilization and treatment.

\section{Discussion}

Since the triumph of the Cuban Revolution in January 1959, the Revolutionary Government gave priority to public health as one of the essential services to society, whose fundamental principles: the extension throughout the country of health services, including remotest places; where all services, even the most sophisticated as in the case of ICME, are made available to all Cubans regardless of sex, skin color, economic and social status and political or religious beliefs; It is free and state responsibility with a national health system only; based on medical ethics, humanism, solidarity and internationalism.

The development of the Cuban public health and medical education have led the country to show health indicators in countries with developed economy, which is contradictory since Cuba does not possess such economic indicators; however, health indicators, the basic picture of morbidity and mortality and international prestige achieved by doctors and health professionals is an unprecedented result in Cuban history.

At present the national Cuban health system works to complete the guidelines of the Party and the Revolution [22] expressing the need to improve the quality of service provided, the satisfaction of the population, improve working conditions and care staff health, ensure efficient use of resources, savings and eliminating unnecessary expenses; reorganize, compact and regionalize health services, including emergency care and medical transportation; strengthen education and employment of clinical and epidemiological method that contribute to the rational use of technological means; and ensure that the training of medical specialists provide a response to the country's needs and those generated by international commitments, all applicable ICME specialist.

Medicine specialties are the first graduate activity scheduled basis was conducted in after the victory of the Revolution Cuba. From 1962 the first medical residency programs in Pediatrics, Internal Medicine, Gynecology and apply Cirugía [23, 24].

The curriculum of the Cuban medical specialties is done on a national basis, based from the historical-cultural perspective in close connection with the activity and communication, it is based on principles of Cuban medical education as the link theory with practice, education with work, integrated into the activities of health care and research, education and tutorial are taken into account other essential components, such as work management, teaching-learning and metodológico [23-26].

For curriculum development model is part of the specialist who aspires to be, values, human qualities and philosophical conception. The professional profile that constitutes the guiding in the training process should be a dynamic, mobile reality, constantly changing and adjustments, according to the demands of society, the conditions for the profession and the scientific, technological, ethical variations, demographic and sociological. It must be a constant dialogue between training institutions, the workplace and professionals, from which emerge the guidelines to readjust training plans $[23,27,28]$. As for 16 years established the program in the specialty ICME Cuba needed transformation according to specialist care system in ICME in Cuba.

There is thus the need for the curriculum ICME relevant, ie be redesigned from the identification of the major health problems of the population, taking into account scientific and technological developments at the national and global levels and that the process training is developed to cover the occupational profile of the ICME, according to the functions and competencies identified by Véliz and collaborators $[9,10]$.

The form of organization of teaching that characterizes the residence in Cuba is education at work, which is done tutorial. The resident participates as a member of the health team, with teachers and specialists, with practical implementation and service performance meets job functions, all activity becomes an educational process where learning by itself, form and develop the abilities and skills that meet the professional functions, acquires working methods and personality traits of a specialist, achieved independence in the diagnosis and treatment of diseases, in 
decision-making, applying creativity and the necessary scientific approach to solve each situation, i.e., in this teaching process, care and integrated research $[24,26,29]$.

Education at work is complemented by other forms of organization of teaching, such as lectures, seminars, literature reviews, practical classes, workshops, courses and independent study, they are also required to make a final research work specialities [21].

According to these characteristics, the principles of integrationcare teaching-research, education at work, tutorial teaching, and study and independent work that characterize the Cuban medical education are met.

Professional performance specialists ICME complex becomes today, which has been imposed by increasing their occupational profile and labor scenarios, which causes the development of certain tasks and responsibilities in the care, management, teaching areas and different research to those found in the curriculum of the specialty [7] so that when performing an occupational functional analysis of professional performance, as an activity in itself, since social reference, has enabled the author to reflections and evaluative integrations investigations have included different groups of specialists, experts, employers and managers to identify professional competences [10] and functions [9] and specialists who develop these services in Cuba.

Currently, the Cuban Society of Intensive Care and Emergency Medicine (Socumie) has been recognized internationally and has joined prestigious international companies, such as the Pan American Federation and Iberian of Critical Care Medicine and Intensive Therapy (FEPIMCTI), the Central American and Caribbean Confederation Intensive Care (COCECATI), the International Federation of Emergency (IFEM), the Latin American Association of Cooperation in Medical Emergencies and Disasters (ALACED), has relationships with many companies from different countries and is willing to join other associations and societies to promote interest in science and the development of human capital.

Specialty programs in the world are dissimilar in: composition, extension, registration requirements, objectives, activities, evaluation and other methodological aspects, there are differences between all countries and there are varieties of curriculum within the same country; in some it is a primary specialty and other is a subspecialty or supraespecialidad, generally divided into adult and pediatric specialists, which is related to the organization of the health system, infrastructure and human resources [30-39].

Currently the population aging, the use of invasive techniques, immunosuppressive drugs, highly complex surgery, solid organ transplants, hematology and oncology lead to a steady increase in demand for intensive care; the presence of specialists in ICUs has been associated with a significant decrease in the average length of stay and hospital mortality; which is required to be competent integrate: scientific knowledge, technical skills and clinics, performance, effective communication with patients, families and other health professionals, cultivate values, provide care and patient care, and understand their cultural and spiritual dimensions $[35,40]$.

In the late twentieth century, it emerged as new specialty of urgency and emergency medicine (UEM), based on knowledge and skills for the prevention, diagnosis and management of diseases, acute and urgent injuries. This practice includes attendance at the reception, resuscitation, prehospital and hospital accident and emergency management, where time is critical [40-43].

Britain, USA, Australia, Canada and Ireland began the UEM, subsequently joining them countries around the world to involve more than 100 who have training in the discipline. Specialists are grouped in national, regional and international scientific organizations, who have tried to standardize a curriculum for speciality [41-43]

The specialist in emergency medicine, among its functions: provides immediate and comprehensive assistance with stabilizing end, regardless of age and injuries or acute illness; manages and makes decisions under time pressure; attends life threatening situations; coordinates and oversees the simultaneous attention of multiple victims, including catastrophes situations [42, 44].

Several authors and multidisciplinary groups of leaders in critical care medicine and emergency medicine [45-49], advocate strongly for interbreeding between the two disciplines and increasing both specialists is a growing reality in the USA, which justified by the improved clinical outcomes and cost savings training, strengthens the provision of critical care in the emergency department and facilitates coordination between the emergency department and ICU, which coincides with the Cuban health care system in the specialty of ICME.

The author wishes to express the importance it has had for this article, for the determination of the functions and powers ICME specialist in Cuba $[9,10]$, the CoBaTrICE project, supported by the European Union and European societies intensive care, whose purpose was to identify the minimum competencies required for the training of specialists in intensive care adult and create a training program accepted in the European area, in line with the objectives of the Bologna Declaration allowing free recruitment of specialists in the region $[50,51]$, that has transformed the curriculum in many European countries [52].

The future of specialist training in ICME in Cuba and their health care system will continue to combine the specialties of medicine intensive and emergency medicine and emergencies, a training system of skills, abilities and knowledge acquired by doctors in training and developed during the performance, which can be considered comparable to global recommendations to provide optimal care to critically ill patients or critical.

\section{Conclusion}

The system of care provided by the specialist in intensive care medicine and emergency in Cuba is a continuous and progressive patient care with emergencies or emergencies from any source, serious or critical, where the patient goes through the various 
stages of the healthcare network and there is always a specialist who devotes all his time to specialized care, with optimal performance in the diagnosis, stabilization and treatment; and combining the knowledge and skills intensive care specialties with emergency medicine.

In specialist training in intensive care medicine and emergency in Cuba the principles of Cuban medical education, given teaching- research-care, education at work, tutorial teaching, and study and independent work integration are met.

It is necessary to update the curriculum of the specialty by increased occupational profile and labor scenarios, which causes the development of certain tasks and responsibilities to the different care, management, teaching and research areas that are in the current program. 


\section{References}

1 Salas Perea RS, Díaz HL, Pérez HG (2016) The competence-based curriculum in the formation of medical specialists. Educ Med Super 27: 262-274.

2 Cuba Ministerio de Educación Superior (2004) Reglamento de la Educación de Posgrado de la República de Cuba. Resolución Ministerial No. 132/2004. Gaceta Oficial de la República de Cuba, edición extraordinaria 2004: 51-58.

3 Roca J, Pérez JM, Colmenero M, Muñoz H, Alarcón L, et al. (2007) Professional competence for the care of critical patients: Beyond specialities. Med Intensiva 31: 473-484.

4 Caballero LA (2006) Historia de los Cuidados Intensivos. In: Caballero LA (edr) Terapia Intensiva. 2da ed. Editorial Ciencias Médicas, La Habana.

5 Lovesio C (2008) Requerimientos generales de una unidad de terapia intensiva. In: Lovesio C (edr) Medicina Intensiva. 6ta ed. Corpus Libros Médicos y Científicos, Rosario.

6 Véliz Martínez PL, Jorna Calixto AR (2014) Historical development and future prospects of the intensive and emergency medicine as specialty in Cuba. Educ Med Super 28: 3.

7 Cuba Ministerio de Salud Pública (1999) Programa de Especialización en Medicina Intensiva y Emergencia. MINSAP, La Habana.

8 Salón CJ (2011) Finlay Relatoría del I Taller nacional y II Coloquio para el desarrollo de la especialidad. Medicina Intensiva y Emergencia, La Habana.

9 Véliz PL, Berra EM, Jorna AR (2015) Definition of specific functions and procedural skills required by Cuban specialists in intensive care and emergency medicine. MEDICC Review 17: 18-26.

10 Véliz PL, Jorna AR, Oramas R (2016) Specific professional competences specialist in intensive care medicine and emergency in Cuba. MEDICC Review, Cuba.

11 República de Cuba (2016) Ministerio de Salud Pública. Anuario Estadístico de Salud 2015. MINSAP, La Habana.

12 United Nations Development Programme (2016) Human Development Indicators. Human Development Reports, Cuba.

13 Expansión/Datosmacro.com (2016) Cuba: Economía y demografía. Expansion, Cuba.

14 Véliz Martínez PL (2014) Intensive municipal areas. Rev Cub Med Int Emerg 13: 1-2.

15 Rodríguez PD, Moreno MM, Rodríguez PJ, Pérez LE (2014) Identification of learning requirements on basic care of medical urgencies and emergencies in the primary health care. Educ Med Super 28: 14.

16 Jorna Calixto AR, Véliz Martínez PL, Cuéllar ÁR (2010) Myocardial acute infarction in integral diagnosis centers of Vargas, Venezuela. Rev Cubana Med Gen Integr 26: 12.

17 Barnés Domínguez JA, González PM (2009) El Contingente Médico Cubano "Henry Reeve". Panorama cuba y salud 4: 5.

18 Seijas GM (2015) Cuban professionalism and dignity against ebola. Rev Cub Med Mil 44: 3.

19 Perez CR (2015) Emergency response to earthquake in Chile: Experience of a Cuban field hospital. MEDICC Review 17: 39-42.

20 Parellada BJ (2001) Medicina intensiva y emergencias: Una nueva especialidad. Rev Cub Med Mil 30: 5.
21 Cuba Ministerio de Salud Pública (2004) Reglamento del Régimen de Residencia en Ciencias de la Salud. Resolución Ministerial No. 108/2004. Ministerio de Salud Pública, Ciudad de La Habana.

22 Lineamientos de la política económica y social del Partido y la Revolución. In: VI Congreso del Partido Comunista de Cuba. Capítulo VI Política Social, Aprobado.

23 Salas Perea RS, Salas MA (2014) Ways of professional performance and their role in the training of doctors. EDUMECENTRO 6: 20.

24 Nolla CN (2001) Los planes de estudio y programas de las especialidades médicas. Educ Med Super 15: 13.

25 Castillo Guerrero LM, Nolla CN (2004) Concepciones teóricas en el diseño curricular de las especialidades biomédicas. Educ Med Super 18: 7.

26 González-Pérez J (2015) Current situation and challenges of the University of Medical Sciences of Havana course 2015-2016. Rev haban cienc méd 14: 6.

27 Ortiz GM, Cires RE (2012) Competence based curricular design. Its application to the macro-curriculum. EDUMECENTRO 4: 10.

28 Hawes G, Corvalán O (2005) Construcción de un perfil profesional. Universidad de Talca, Chile.

29 Salas PR, Salas MA (2012) Cuban medical education. Its current status. Revista de Docencia Universitaria 10: 34.

30 Barrett H, Bion JF (2005) An international survey of training in adult intensive care medicine. Intensive Care Med 31: 20.

31 Navarrete NP, León GC, González DG (2011) Intensive medicine in Europe: A need. Med Intensiva 35: 3.

32 Junta Directiva de la Sociedad Española de Medicina Intensiva, Crítica y Unidades Coronarias (2011) Intensive medicine in Spain. Med Intensiva 35: 20.

33 Artigas A, Pelosi P, Dellweg D, Brochard L, Ferrer M, et al. (2012) Respiratory critical care HERMES syllabus: defining competencies for respiratory doctors. Eur Respir J 39: 14.

34 Vera CO (2012) Programas académicos de la residencia médica en medicina crítica y terapia intensiva. Rev Méd La Paz 18: 25.

35 Gálvez S, González H, Labarca E, Cornejo R, Bruhn A, et al. (2013) Ministry of Health Intensive Care Medicine Commission. Proposals for the development of the discipline. Rev Méd Chile 141: 10.

36 Universidad Nacional Federico Villarreal (2013) Facultad de Medicina Humana Hipólito Unanue. Programa de Segunda Especialización Residentado Médico. Plan Curricular de la Especialidad de Medicina Intensiva. Universidad Nacional Federico Villarreal, Lima, Perú.

37 Vázquez GR (2013) Aspects worth knowing about intensive care medicine in the United States. Med Intensiva 37: 11.

38 Bion J, Rothen HU (2014) Models for Intensive Care Training. A European Perspective. Am J Respir Crit Care Med 189: 24.

39 Prisco L, Donadello K, Shepherd SJ (2015) Intensive care medicine curricula in Europe: docendo discimus. Intensive Care Med 41: 10.

40 Castellanos-Ortega Á, Rothen HU, Franco N, Rayo LA, Martín-Loeches I, et al. (2014) Training in Intensive Care Medicine. A challenge within reach. Med Intensiva 38: 18.

41 Ohlen G, Petrino R, Vázquez Lima MJ (2009) La formación en Medicina de Urgencias y Emergencias. Emergencias 21: 2.

42 Hobgood C, Anantharaman V, Bandiera G, Cameron P, Halpern P, et al. (2011) International Federation for Emergency Medicine model 
curriculum for emergency medicine specialists. African Journal of Emergency Medicine 1: 22.

43 Totten V, Bellou A (2013) Development of Emergency Medicine in Europe. Acad Emerg Med 20: 16.

44 Petrino R (2009) A curriculum for the specialty of emergency medicine in Europe. Eur J Emerg Med 16: 113-114.

45 Huang DT, Osborn TM, Gunnerson KJ, Gunn SR, Trzeciak S, et al. (2005) Critical care medicine training and certification for emergency physicians. Ann Emerg Med 46: 217-223.

46 Mayglothling JA, Gunnerson KJ, Huang DT (2010) Current Practice, Demographics, and Trends of Critical Care Trained Emergency Physicians in the United States. Academic Emergency Medicine 17: 11.

47 Green RS (2006) Response to: Critical Care Medicine Training and Certification for Emergency Physicians. Ann Emerg Med 48: 2.
48 Grossman MD (2009) Further Support of the Emergency Intensivist. Critical Care Medicine Section Newsletter 10: 3.

49 Shiber J (2014) Contribution of emergency medicine-critical care medicine physicians to the intensivist workforce. Crit Care Med 42: e486.

50 CoBaTrICE Collaboration, Bion JF, Barrett H (2006) Development of core competencies for an international training programme in intensive care medicine. Intensive Care Med 32: 20.

51 Rubulotta F, Moreno R, Rhodes A (2011) Intensive care medicine: Finding its way in the "European labyrinth". Intensive Care Med 37: 12.

52 The CoBaTrICE Collaboration (2009) The educational environment for training in intensive care medicine: Structures, processes, outcomes and challenges in the European region. Intensive Care Med 35: 18 